\title{
Historias de la tercera edad: entre la continuidad y la alteridad
} Histórias de terceira idade: entre a continuidade e a alteriedade Third-age stories: between continuity and alterity http://dx.doi.org/10.5007/2178-4582.2017v51n2p477

\author{
Alejandro Klein e Erika Carcaño \\ Universidad de Guanajuato, León/Gto, México
}

\begin{abstract}
Este artículo busca replantear algunas cuestiones de cómo nos acercamos a la vejez hoy, señalando que pasamos de términos relativamente claros (vejez y el envejecimiento) a una polisemia de conceptos que entran dentro de lo que se denomina paradigmas anacrónicos o ambiguos. Se insiste en que el tema del envejecimiento es reemplazado probablemente por dos grandes polos: una estética no decrépitos y una actitud de memoria resiliente, los que son ejemplificados en dos estudios de caso. En ambos casos se plantea una etapa de alta experimentación subjetiva, tratando de localizar la situación del envejecimiento desde parámetros sociales y culturales más amplios

Palabras clave: vejez; experimentación subjetiva; renovación social.
\end{abstract}

Este artigo procura repensar algumas questões sobre como abordamos a velhice hoje, observando que passamos de termos relativamente claros (velhice e envelhecimento) para conceitos polissemicos que se enquadram nos chamados paradigmas anacrônicos ou ambíguos. Afirma-se que a questão do envelhecimento é provavelmente substituida por dois pólos principais: uma estética não decrépita e uma atitude de memória resiliente, que são exemplificados em dois estudos de caso. Em ambos os casos, propõe-se um estágio de experimentação subjetiva alta, tentando localizar a situação do envelhecimento a partir de parâmetros sociais e culturais mais amplos.

Palavras-chave: idade avançada; experimentação subjetiva; renovação social.

\section{Introduccion}

Hasta hace unas décadas la construcción de subjetividad tenía un claro límite: la vejez. Llegado a cierto punto, la jubilación indicaba el fin de cualquier promesa y el comienzo del fin, es decir, la vejez no anticipaba sino el signo impostergable de la muerte como fin de cualquier anticipación, descartando claro está, posibles opciones religiosas.

Sin embargo, las cosas han cambiado. Desde hace unas décadas la vejez no anticipa la muerte, sino una renovación de nuevas formas de experimentación social, cultural y especialmente subjetiva. No toda la población vieja participa de este nuevo clima cultural totalmente, pero nuestra hipótesis es que en mayor o menor grado la tercera edad se encuentra en un alto grado de experimentación subjetiva que va al menos desde un polo rupturista (caso Juan) hasta un polo resiliente (caso Pascuala). Lesson (2013) habla del siglo XXI como de una "revolución gerontológica", nosotros agregaríamos al concepto la existencia de una "extrema revolución subjetiva". 


\section{Antecedentes}

Se puede situar entre el siglo XVIII y el transcurso del siglo XIX la fijación del estereotipo del anciano en sus aspectos clásicos: debilidad, precariedad $\mathrm{y}$ enfermedad, aspectos que se relacionan con la imposición del término "senil" para caracterizar al mismo (KATZ, 1996). Especialmente el cuerpo del anciano aparece como en un proceso de déficit y pérdida permanente que se vuelve un proceso crónico e irreversible (KATZ, 2000).

El envejecer fue definido como una enfermedad progresiva responsable de una multitud de cambios fisiológicos y anatómicos (HABER, 1986). Se hablaba en este sentido de: "degeneración progresiva" (KATZ, 1996) como si fuera un estado normal y esperable.

De esta manera el anciano era un ser improductivo e inútil socialmente. La observación de Iacub (2006) en este sentido es relevante: se concebían dos muertes, una para la sociedad y la otra era la muerte individual. El sujeto se iba apartando cada vez más de la vida y la sociedad, aislándose en su propio mundo (CUMMING; HENRY, 1961). Se podría también analizar cómo estos procesos se asocian a diversos procesos de disciplinamiento y control cultural (COLE ,1997).

Sin duda se puede señalar que existe una historia cultural del envejecimiento, que indica que el concepto mismo es difuso y altamente cambiante según circunstancias históricas y contextos culturales, lo que implica que aquello que tradicionalmente se ha caracterizado como "científico" en el tema se ha revelando en realidad prejuicioso y paradigmático (BOURDELAIS, 1993)

Desde el siglo XX esta concepción "degenerativa" y "senil" se comienza a modificar simultáneamente a un replanteamiento crítico del significado de las “edades" y como se construía la biografía personal (MEYROWITZ, 1984). O la edad se vuelve un factor descriptivo irrelevante (IACUB, 2006) o se considera que entramos en una sociedad "uniage" donde las fronteras entre edades se difuminan y tienden a unificarse (NEUGARTEN, 1999).

Al mismo tiempo se alienta una revisión crítica de la noción de envejecimiento desde la segunda mitad del siglo XX (BUTLER, 1969). Se comienza a poner el acento más en la continuidad que en la discontinuidad, en la resiliencia y el potencial más que en la pérdida y el déficit y en las potencialidades y posibilidades que el envejecimiento podría implicar (ATCHLEY, 1977; NEUGARTEN, 1964; ROSOW, 1963). Se plantean nuevas formas de inserción social (EKERDT, 1986) y lo que el anciano puede aportar a la sociedad desde el concepto de "envejecimiento exitoso" (BALTES et al.,1984). 
Para Baltes, justamente el envejecimiento exitoso depende del esfuerzo aplicado a dominios donde se mantiene potencial de desarrollo, lográndose a través de dicho esfuerzo una optimización de la funcionalidad, la que compensa las pérdidas normativas y no- normativas ocasionadas por el envejecimiento social y biológico.

Por otro lado para Rowe y Kahn (1997, 1998), la posibilidad de envejecimiento exitoso se relaciona con dos tipos fundamentales de actividad: el primero es el mantenimiento de relaciones interpersonales satisfactorias y el segundo es el mantenimiento de actividades productivas.

Lo que estos autores llaman compromiso "activo" con la vida es un factor relevante, junto al adecuado funcionamiento físico y cognitivo (es decir: la capacidad de mantener un factor de autonomía y autocuidado, entre otros) y la baja probabilidad de padecer enfermedades crónicas (y los riesgos asociados a ellas).

En definitiva entendemos que los autores proponen un modelo de vejez en la cual el adulto mayor puede enfrentar y resolver de manera autónoma sus problemas insertos en actividades cotidianas. Para estos autores los componentes mencionados están ligados y se retroalimentan entre sí.

Por ejemplo, es posible constatar que la ausencia de enfermedad o discapacidad contribuye a que se mantengan las funciones físicas y mentales necesarias para facilitar una participación activa en la vida social. Es interesante indicar que al igual que Baltes (1984) enfatizan la necesidad de la participación o compromiso con la vida como un factor esencial, lo que se relaciona con las hipótesis manejadas en este artículo de un replanteamiento del sentido de la vida en los adultos mayores contemporáneos, donde entendemos como compromiso con la vida, la posibilidad de armar o configurar proyectos de vida satisfactorios que incluyen las relaciones interpersonales, alta autoestima e inserción social.

Podría indicarse que el concepto de envejecimiento exitoso se está complejizando, en el sentido de que el mismo ya no se entiende solo como la ausencia de enfermedades, sino como la reformulación que el adulto mayor realiza de su inserción en la vida social, además de cómo reconfigura su biografía personal en términos de realizaciones y porvenir.

\section{Revision empírica: la revolución gerontológica desde los aportes de la demografia y las ciencias sociales}

El Instituto Nacional de Estadística y Geografía (INEGI, 2010) registró en México, un total de 10, 055,379 adultos mayores, de los cuales el 53\% 
son mujeres, mientras que el $47 \%$ son hombres. De acuerdo con la tasa de crecimiento anual en México, entre 1990 y 2010 el número de adultos mayores pasó de 5 a 10.1 millones, presentándose un incremento porcentual respecto al total de la población de 6.2 a 9 (INEGI, 2011). Estos datos indican claramente que México ha entrado en lo que se denomina "envejecimiento poblacional". Esto se une a la creciente baja de la tasa de crecimientos (INEGI, 2005).

Todo lo cual hace que se hable de nuevos procesos de transición demográfica que de acuerdo con los especialistas en población, implicará una tercera etapa de transición demográfica (DYSON, 2010; LEESON; HARPER, 2006, 2007, 2007a, 2007b, 2008), dominada por una revolución gerontológica, por la cual se entiende que el siglo XXI es el siglo de los "centenarios" (LEESON, 2009, 2013).

En este sentido, y de acuerdo con las estimaciones realizadas por el Consejo Nacional de Población (CONAPO, 2005), se estima que del año 2010 en adelante, "las personas de 65 años vivieran alrededor de 15 años más, expectativa que mostrará una tendencia a aumentar todavía más en los años venideros, manteniéndose cada vez más una etapa de sobre-mortalidad en dicho periodo de la vida" (VILLAGÓMEZ, 2009, p. 307).

Por otro lado si tenemos en cuenta el porcentaje de adultos mayores en la totalidad de la población, la Cepal (2009) estima que en el año 2010 la proporción de personas con 60 años y más en la región fue de $9.9 \%$, para el 2020 será de $13 \%$, y para el 2050, de $25.8 \%$ Asimismo para 2010 la población de adultos mayores en Latinoamérica fue de 590 millones de personas, incrementándose este número en los años siguientes (LEESON, 2013).

Por otra parte no solo hay más adultos mayores sino que los mismos viven cada vez más, sin que haya por el momento un límite al alargamiento del curso de la vida (LEESON, 2009), lo que a nuestro entender se puede conceptualizar como el pasaje a una muerte desplazada indefinidamente, hecho sin duda inédito y crucial.

Es necesario indicar que el nivel de envejecimiento que presentan México y la mayoría de los países de la Región se ha alcanzado en medio siglo, en comparación con Europa, donde este proceso tomó dos siglos (CAMARANO, 2004; HAM CHANDE, 2003; VIVEROS, 2001). En el caso de Latinoamérica y el Caribe se indica que los mismos están próximos a enfrentar enormes desafíos en el área del envejecimiento global, junto con la necesidad de incluir el tema en las agendas de gobierno (BREA, 2003).

Estos mismos procesos, como se indicó, se verifican en Europa y otros países. Se indica así que la proporción de personas de 60 años será el $22 \%$ de la población total para el año 2050 (UNITED NATIONS, 2010). 
Estos datos son tomados generalmente de forma alarmante, punto de vista que no se comparte en este trabajo. Se habla así de crisis de la seguridad social (lo que sin duda es un hecho que estará presente), inseguridad económica y aumento de enfermedades mentales y físicos.

Sin desconocer los mismos tenemos en cuenta otros datos que nos indican un mundo cambiante y quizás imprevisible en algunos elementos de su estructura social. Especialmente se indica la revolución gerontológica como produciendo desafíos y oportunidades para gobiernos y ciudadanos en el mundo entero (LEESON; HARPER, 2006, 2007, 2007a, 2007b, 2008):

\begin{abstract}
The challenge of increasing longevity has long been an issue of demographic interest, and no less so in more recent years The scale of ageing across the globe is truly immense and must surely be regarded as one of the success stories of humankind as more and more people live long, relatively healthy lives. (LEESON, 2013, p. 53).
\end{abstract}

Otros autores son más optimistas aún y señalan un cambio en la estructura del trabajo y en la economía que implicará un dividendo demográfico (LEE; MASON, 2010), estimando que existirán los recursos necesarios para asistir a la población envejecida (HELLER, 2006).

Desde una perspectiva social hay datos que indican también aspectos positivos e integrativos culturalmente para los adultos mayores, como la posibilidad de resignificación del yo (CASTRO, 2001); la contribución cultural de los adultos mayores a las nuevas generaciones Bosi (1994); el acrecentamiento de la voluntad de vivir y replantear historias y tradiciones culturales (MORAGAS ,1991); nuevas formas de aprendizaje (LOPEZ LA VERA, 2013); replanteamiento y valorización de la vida en pareja (KEMP; KEMP, 2002); de la sexualidad, el amor y la satisfacción marital (BACHAND; CARON, 2001; KASLOW; ROBINSON, 1996; NINA-ESTRELLA, 2004; NOLLER; FITPATRICK, 1993; PARKER, 2000); y finalmente el factor de generatividad entendido como la capacidad de enfrentar retos y fortalecerse subjetivamente ( ERIKSON, 1950).

Explícitamente se indica como los adultos mayores hoy no solo son más longevos, sino que disfrutan de mejor calidad y estilos de vida (VILLAR, 2013). Pensamos que es posible relacionar las nuevas formas de autopercepción y construcción de identidad con la llamada teoría de la desvinculación o de desengache y ruptura. Se entiende por la misma que el adulto mayor se aparta de la sociedad para centrarse más en su vida interior, lo que lo independiza de obligaciones sociales incrementando su capacidad de satisfacción (Havighurst, Neugarten, y Tobin; citados en CARSTENSEN, 1990). Sin embargo, como 
veremos más adelante, quizás sea más apropiado hablar de "cambio" que de "apartamiento" en el vínculo con la sociedad

Estas perspectivas indican la necesidad de cambiar la imagen de los adultos mayores como una "carga" para destacar su valor como recurso social y cultural, lo que se complementa al dato fundamental, de que cuando el mismo tiene los recursos necesarios, depende menos de su familia, la que pasa a segundo plano, lo que se acompaña de la ampliación de redes sociales y de amistad, lo que acrecienta además el sentido de vitalidad (LÓPEZ LA VERA, 2010, 2013; PICK, 2007; SÁNCHEZ, 2002).

Otros autores prefieren tomar estos datos como reveladores de empoderamiento y agenciamiento, basados en investigaciones que indican el deseo de los adultos mayores de tomar el "control" de sus vidas (SORIA, 2006), incrementado el sentido del yo y de confianza en sí mismo (SÁNCHEZ, 2002) y la capacidad de enfrentar nuevos aprendizajes y desafíos derivados de los mismos (LÓPEZ LA VERA, 2013).

Guzmán, Huenchuan y Montes de Oca (2003) plantean que el cumplimiento de una vejez activa requiere que el Estado asuma un rol activo en mejorar las condiciones de vida de los adultos mayores. Perspectiva con la cual sin embargo discrepamos: los adultos mayores han modificado sus posibilidades de vida con, sin o contra el Estado. Posiblemente esto esté relacionado a que las redes sociales substituyen aquello en lo cual aquél es carente (MENDES DE LEON et al., 1999; MONTES DE OCA, 2004, 2009; UCHINO, CACIOPPO; KIECOLT-GLASER, 1996).

Se ha comprobado que poseer una red social adecuada tiene innúmeros efectos positivos en el área de la salud física y mental, mejorando asimismo la autopercepción que los adultos mayores mantienen sobre sí mismos, acrecentando el sentido de satisfacción vital (IRVINE et al., 1999; GAETE; RIVERA; ROMAN, 2009; MUCHINIK, 1984).

Así pues los fenómenos que describimos en relación al desplazamiento de la muerte se respaldan en numerosas investigaciones demográficas, antropológicas, psicológicas y sociológicas, tanto desde autores norteamericanos y europeos, como latinoamericanos y mexicanos, todos los cuales describen diferentes aspectos inherentes a la sociedad del envejecimiento y la revolución gerontológica.

\section{El caso de juan: el franco rupturismo generacional-transgeneracional}

Juan tiene 70 años de edad. Pero no los parece. A lo sumo podríamos darle 55 años. Vive en la ciudad de Querétaro, México. Pertenece a la clase media, 
media alta. Sin apremios económicos o sociales. Ya desde su apariencia personal Juan es francamente rupturista y alejado de cualquier estética decrépita: "Sé que no me visto como viejo. No quiero parecer viejo. No me siento viejo. Me gusta ser abuelo pero no un hombre débil o que necesito ayuda...Me gusta estar con mis nietos por el gusto de estar nomás. No necesito que me ayuden en mi vida"

\section{Preguntado sobre sus rutinas nos dice:}

Voy al gimnasio. No tanto como querría pero voy al menos tres veces a la semana. No como cosas grasosas. Mi esposa y yo somos cuidadosos en lo que comemos. Preferimos el agua a la Coca Cola. Hace 30 años que estamos juntos. No le he sido infiel. Es cierto que fumo de vez en cuando. Ese vicio no me lo puedo sacar. Hace poco me jubilé de profesor en la Universidad XXX, pero mi vida no se termina. Sigo haciendo cosas. Manualidades o leo. Veo a mis amigos, pero lamentablemente algunos tienen Alzheimer o demencia. No los voy a ver. Yo no soy viejo como ellos. Quiero ser joven y tener vigor.

No nos quiere hablar de su sexualidad con un sentido de pudor que respetamos, pero su cara se ilumina de orgullo cuando nos dice: "Sabe?. Yo no voy al parque a darle miguitas a las palomitas. Nada de eso. Yo no me aburro. Y me jubilé porque tenía que jubilarme sino seguía de largo nomás". Cuando le preguntamos sobre sus abuelos dice:

Mis abuelos eran buena gente. No recuerdo que nos pegaran. Tendría que preguntar a mis hermanos [tiene dos hermanos menores]. Pero eso sí había que respetarlos. Tratarlos de "usted". Mis nietos me hablan de otra manera. Me tutean. Pero me gusta. Yo entiendo que antes las cosas eran así. Pero ahora ya no. Tenemos confianza, nos hablamos las cosas. Mis nietos me preguntan cosas que yo jamás me hubiera atrevido con mis abuelos. Y me cuentan cosas de su vida íntima que me chocan un poco pero me pone orgulloso que me las cuenten. Para eso está un abuelo.

Cuándo les preguntamos cómo les educa, nos dice (pensando largo rato):

Educarlos...? Ah no sé. Tengo que pensarlo. Educarlos? No creo que no. Eso es de sus padres. Yo no me meto. Conmigo que salgan, vamos al cine, a comer, a pasear. Pero no quiero educarlos, para eso están mis hijos [Juan tiene dos hijos, cada uno con un hijo propio]" Y agrega: "Yo respetaba y respeto a mis abuelos. Pero yo soy otro abuelo, no sé si mejor o peor. Ud dígame. Pero lo más importante para mí es el cariño y la confianza. 


\section{El caso de pascuala: la memoria resiliente como forma comunitaria de vida}

Citemos el caso de Pascuala, que tiene actualmente 65 años de edad y vive en una Comunidad llamada "Cautamazaco" [en náhuatl: lugar de venados] perteneciente al Municipio de Cuetzalan, en Puebla, México Se describe a sí misma como una mujer activa, aún fuerte, independiente y con una decisiva influencia en su comunidad. En efecto, Pascuala pertenece a la Organización de Mujeres Indígenas (MASEAL SIGUAMEJ), que en náhuatl significa: "Mujeres que se apoyan y trabajan juntas". Dentro de esta organización es socia, pero además mantiene un liderazgo activo sobre los más jóvenes debido a sus conocimientos ancestrales de ritos y tradiciones indígenas.

Ella elabora y vende sus artesanías que consisten en prendas elaboradas con telar de cintura. Dice de sí misma: " Soy una mujer feliz, no me falta comida, estoy contenta con lo que hago. Tengo varios hijos e hijas. No todos viven conmigo. Pero yo nunca estoy sola. La tierra me acompaña. Yo hablo con la tierra. Vengo de la tierra". Nos cuenta orgullosa como recién en la tercera edad decidió hacer su vida independiente y por eso se separó de su marido quien tenía una amante y le prohibía participar en sus actividades comunitarias.

Nos cuenta que es feliz como líder comunitaria, que le gusta dar el ejemplo a los jóvenes y que hasta cierto punto todos los miembros de la comunidad son como "sus hijos".

Cuando le preguntamos sobre su relación con la tierra, nos dice:

\footnotetext{
"Es como una madre que nos acompaña. Conozco sus historias y sus secretos. Nunca le hablo en español sino en náhuatl de acuerdo a lo que mi madre y la madre de mi madre me enseñaron. Los hombres no saben estas historias. Solo nosotras las mujeres. Y las repetimos una y otra vez hasta que las jóvenes lo saben repetir de memoria. Yo recuerdo todo lo que me enseñaron y mi nieta también. Y lo que me enseñaron fue a cuidar a nuestra madre tierra, gracias madre tierra. (Tlazocamati Tonantzin)
}

Cuando le preguntamos por qué agradece a la madre tierra nos dice: "La madre tierra nos da el sustento. Nos alimenta. Pero también es nuestra tierra. La recordamos y nos recuerda. Nunca nos abandonará"

Pascuala está muy orgullosa de que a partir de que se separa, junto al trabajo con otras mujeres de su condición, trabaja y se compra su propia casa. Utiliza activamente los recursos que le proporciona la Comunidad de Mujeres, 
manteniendo siempre una actitud activa, comprando su terreno a partir de un programa municipal, donde el Municipio pone una parte y ella otra.

Finalmente cuando se le pregunta si se siente una mujer anciana, riendo, responde: "Aún tengo todos los dientes. Me levanto siempre a las 6 de la mañana y cuido de mis pollos y gallinas. Me sé cuidar a mi misma. Veo que mis hijos estén bien y jamás se me ocurre volver con mi esposo que no me respetó" "Hice que mi hija volviera conmigo luego que se la robó un hombre malo. Yo la salvé. Le hablé a una amiga y esa amiga le habló a mi hija y ahora ella ya está conmigo". "Yo como bien y siempre le dejo comida a mis hijos" "No quiero que me pidan de comer. Solo les dejo la comida y ellos se sirven"

\section{Conclusiones}

En el caso del transcurso de vida de Juan lo que encontramos es que un valor que se acentúa es la independencia. Juan es un abuelo que a diferencia de los abuelos de antes ya no se les ocurre pensar que tienen que vivir con sus nietos. El concepto de "familia extendida" le es extraño o no lo comparte. Es decir, parece que para esta generación de abuelos es esperable que los hijos vivan en sus casas con sus hijos, y ellos vivan en sus propias casas con su pareja o viven solos. Y sí viven con sus familias, tratan de encontrar estrategias para ser lo más independientes que se pueda.

Por otro lado, por su situación socio-económica hay otra diferencia radical con otros grupos sociales: los nietos están planificados; o sea, el nieto llega después de que el hijo o que la hija terminaron de hacer estudios superiores, o que ocuparon una posición gerencial; o sea, llegan dentro de una planificación de la vida. Estos abuelos además no mantienen ni a la familia ni a los nietos. Sus hijos se mantienen a sí mismos y sienten orgullo de que sus hijos están creando sus propias familias. La mayoría de estos abuelos perciben a sus hijos como buenos padres,y no critican (aparentemente) a sus hijos.

Sienten que no se les necesita en el lugar de los padres porque los padres están haciendo una buena tarea y, además tampoco quieren estar en el lugar de los padres, lo que no les interesa. En otras palabras, y para decirlo de forma redundante, donde están los padres están los padres, y donde están los abuelos están los abuelos.

Y el ejemplo de Juan parece indicar el deseo de que las cosas sigan así: discriminadas y separadas. Ahora bien, en este grupo la palabra clave para nosotros fue estar pendientes. Es decir, Juán no está presente en la vida de los nietos todo el tiempo, pero lo que sí está es estar pendientes. 
Estos son abuelos que les gusta improvisar con sus nietos, no les gusta tener una agenda de lunes, martes, miércoles, domingo. Juan disfruta el sentido de la aventura con sus nietos, más que una planificación rígida, ajustada de tareas, donde se efectiviza un encuentro afectivo siempre renovado.

El abuelo ideal es obviamente el abuelo disponible y esto es muy importante. No es un abuelo que está ausente ni que es invasivo. Es un abuelo que mantiene una distancia óptima con sus nietos y con los padres de sus nietos

Pero lo más importante a los efectos de nuestras hipótesis es que Juan es un claro "emergente" de un grupo claramente "rupturista": quieren ser abuelos pero no abuelos como sus abuelos. Se trata de una verdadera confrontación transgeneracional (KLEIN, 2002, 2003, 2006) que se puede incluir dentro de un campo de alta y sensible experimentación subjetiva.

Por qué esta negativa a ser abuelos como sus abuelos? En primer lugar, porque aquellos abuelos eran "patriarcas" que ellos se niegan a seguir siendo. En un mundo altamente horizontalizado y fraternal donde lo fundamental es la espontaneidad, la figura del "Patriarca" ejemplar, digno, respetable y temeroso se agota. Juan construye su nuevo rol por ensayo y error, no por arquetipos que le preceden. Quiere ser imperfecto y no le causa dolor ser imperfecto. Por el contrario: lo ubica como centro del intercambio afectivo con sus nietos, que por momentos son nietos, por momentos cómplices, por momentos camaradas.

La historia de Pascuala, a su vez, es la de muchas mujeres campesinas de la tercera edad de extractos sociales humildes, que guardan como un "tesoro" inconmensurable esa condición que llamamos "memoria resiliente". Lo curioso es que comienzan sus procesos emancipatorios en la tercera edad, cuando ya siente que sus hijos ya son grandes y no dependen directamente de ella.

Este proceso resiliente tiene que ver con los pueblos indígenas, pero también de forma articulada con los propios derechos de las mujeres y la reivindicación de la tercera edad como etapa de nuevo comienzo en la vida y alta experimentación social y subjetiva (Klein, 2010b, 2013). Esto implica reconocer al interior de la comunidad, la pluralidad y diversidad de identidades y derechos particulares que paralelamente a los componentes centrales de la autonomía como: el territorio, la organización social, uso de los recursos, órganos de gobierno, "se acompañan del derecho de las mujeres de tercera edad a ser agentes de cambio, legitimadas en su derecho a opinar, decidir, elegir y participar en la toma de decisiones en todos los ámbitos y niveles" (MANCINAS ESPINOZA y GARAY VILLEGAS, 2013:404).

Como nos muestra el ejemplo de Pascuala, aunado a lo anterior se ha dado una fuerte tendencia en las últimas décadas a la conformación de organizaciones 
colectivas de mujeres indígenas que ponen en práctica proyectos productivos que generan excedentes y que contribuyen al fortalecimiento comunal. Estas organizaciones de mujeres en muchos de los casos se han conformado mediante un proceso de resistencia de orden cultural de género que desemboca en una toma de decisión colectiva (MEJÍA, 2010) que las lleva a luchar por nuevos pactos sociales y nuevas estrategias comunitarias.

Estas nuevas estrategias comunitarias en las que se incorporan nuevas feminidades y nuevos procesos etarios, superan la visión de muchos estudios rurales en los que se muestran a los sujetos sociales como actores pasivos o condenados a un futuro pesimista. Por el contrario: se deja de lado la idea reduccionista de que las mujeres rurales se centran en actividades tradicionales de su género y dentro de la esfera de la reproducción, dando paso a una realidad en la que ellas forman parte esencial dentro de formas originales de recrear la "comunalidad".

Todos estos cambios de alta experimentación subjetiva implican la aparición de lo que se denomina paradigmas "ambiguos" (KLEIN, 2010a, 2010c), es decir la situación de cómo denominar aquello que recibía una denominación tradicional y consensuada y que ya no se puede utilizar, lo que implica que cualquier denominación no ha de ser sino acotada, injusta o generadora de malestar. En el caso peculiar que nos ocupa del envejecimiento, cualquiera sea la denominación que usemos ésta será incómoda. Se trata de "viejos"? Sí y no. Se trata de "adultos mayores"? Sí y no. Se trata de la "tercera edad"? Sí y no. Estos malentendidos conceptuales que son también ambigüedades conceptuales, no indican sino que estamos ante nuevas modalidad culturales (que algunos denominarán de posmodernas) y de construcción de subjetividad.. Hipotéticamente llamaremos a esta nueva estructura psicosocial de "viejos-no viejos" o "adultos post-adultos"

Estimamos que si tomamos el grupo "rupturista" de los viejos, su escándalo actual radica en que ya no aceptan ser viejos. No aceptan el mandato generacional de la decrepitud, por así decirlo. En ese punto hacen una verdadera confrontación transgeneracional con resultados imprevisibles. Creemos que bien se podría hablar, en tal sentido, como ya mencionamos, de una revolución gerontológica.

El caso del grupo social de Pascuala no es ajeno a este proceso. Pascuala tampoco se siente "decrépita", pero el punto más importante es que su "jovialidad" no es un gesto solitario como el de Juan, sino desde un movimiento emancipatorio que le permite mantener una actitud de agenciamiento.

Cómo continuarán las vidas de Juan y Pascuala? No creemos que cambien mucho. En un mundo donde sentirse bien, holgado y feliz se hace cada vez más difícil, ellos parecen sentirse muy bien, felices, holgados... Esta tendencia 
cambiará? Todo parece indicar que no, pero sus consecuencias en términos de consolidación de nuevas formas de subjetividad, vínculos familiares y matrices culturales es aún impredecible. Este trabajo busca señalar estos aspectos y proponer una reflexión sobre los mismos.

\section{Referencias}

ATCHLEY, R. The Social Forces in Later Life. An Introduction to Social Gerontology. Wadsworth: Belmont, 1977.

BALTES, P., DITTMANN-KOHLI, F.; DIXON, R. "New Perspectives on the Development of Intelligence in Adulthood: Toward a Dual-Process Conception and a Model of Selective Optimization with Compensation". Life-Span Development and Behavior, v. 6, p. 33-76, 1984.

BREA, J. "Population dynamics in Latin America”. Population Bulletin, v. 58, p. 1-36, 2003.

BUTLER, R. “Ageism: Another Form of Bigotry”. The Gerontologist, v. 9, p. 243-246, 1969.

BOSI, E. Memórias e sociedade, lembranças de velhos. São Paulo: Companhia das Letras, 1994.

BOURDELAIS, P. L'Âge de la vieillesse. Histoire du vieillissement de la population. Paris : Odile Jacob, 1993.

BACHAND, L.; CARON, S. "Ties That Bind: A Qualitative Study of Happy Long- Term Marriages”. Contemporary Family Therapy, v. 2, n. 21, p. 105-121, 2001.

CAMARANO, A. A. Os novos idosos brasileiros: muito além dos 60? Rio de Janeiro: Ipea, 2004.

CARSTENSEN, L. "Cambios relacionados con la edad en la actividad social". In CARSTENSEN, L.; EDELSTEIN, B. A. (Eds.). Gerontología clínica. Intervención sicológica y social. Barcelona: Martínez Roca, 1990, p. 58-73.

CASTRO, O. Envelhecer, um encontro inesperado? Sapucaí do Sul: Notadez, 2001.

CEPAL. "Políticas públicas y crisis de cuidado en América Latina: alternativas e iniciativas". In Panorama Social de América Latina. Santiago de Chile: Cepal, 2009, p. 227-240.

COLE, T. The Journey of Life. Cambridge: University Press, 1997.

CONSEJO NACIONAL DE POBLACIÓN [CONAPO]. "EI envejecimiento de la población en México", 2005. Recuperado de <www.conapo.gob.mx/publicaciones/enveje2005/ enveje02. pdf $>$.

Cumming, E.; WILliaM, H. Growing Old: The Process of Disengagement. New York: Basic Books, 1961. 
DYSON, T. Population and Development. London: Zed Books, 2010.

EKERDT, D. "The Busy Ethic: Moral Continuity between Work and Retirement". The Gerontologist, v. 26, n. 3, p. 239-244, 1986.

ERIKSON, E. Childhood y Society. New York: Norton, 1950.

GAETE, J. M. et al. "Aplicación del modelo de redes personales al estudio de los ancianos dependientes”. Revista Multidisciplinaria de Gerontología, v. 19, n. 3, p. 121-129, 2009.

GUZMÁN, J. M., HUENCHUAN, E.; MONTES DE OCA, V. Redes de apoyo social de personas mayores: marco teórico conceptual. Notas de Población, v. 37, 35-70. 2003. Recuperado de http://www.eclac.org/publicaciones/xml/0/14200/lclg2213_p2.pdf.

HABER, C. "Geriatrics: A Specialty in Search of Specialists". In VAN TASSEL, D.; STEARNS, P. (Eds). Old Age in Bureaucratic Society: The Elderly, the Experts, and the State in American History. Greenwood Press: Westport, 1986, p. 66-84.

HAM CHANDE, R. El envejecimiento en México: el siguiente reto de la transición demográfica. México: Porrúa, 2003.

HELlER, P. Is Asia Prepared for an Aging Population? IMF Working Paper WP/06/272. Washington, DC: International Monetary Fund, 2006.

IACUB, R. Erótica y Vejez. Perspectivas de Occidente. Buenos Aires: Paidós, 2006.

INEGI. Los adultos mayores en México 2005, Perfil sociodemográfico al inicio del siglo XXI. Recuperado de http://www.inegi.org.mx/prod_serv/contenidos/espanol/bvinegi/ productos/censos/poblacion/adultosmayores/Adultos_mayores_web2.pdf.

INEGI.CensodePoblaciónyVivienda2010. Recuperadode http://www3.inegi.org.mx/sistemas/ biblioteca/detalle.aspx? $\mathrm{c}=27626 \& \mathrm{~s}=$ est \&upc $=702825002061 \& \mathrm{pf}=\mathrm{Pob} \& \mathrm{f}=2 \& \mathrm{cl}=0 \& \mathrm{tg}=0$.

INEGI. Estadísticas a propósito del día Internacional de las Personas de Edad, 2011 Recuperado de http://www.inegi.org.mx/inegi/contenidos/espanol/prensa/aPropositom. asp? $\mathrm{s}=$ inegi\&c $=2811 \& \mathrm{ep}=71$.

IRVINE, J. et al. "Depression y Risk of Sudden Cardiac Death after Acute Myocardial Infarction, Testing for the Confounding Effects of Fatigue". Psychosomatic Medicine, v. 61, p. $729-737,1999$.

KASLOW, F.; ROBINSON, J. "Long-Term Satisfying Marriages, Perceptions of Contributing Factors. The American Journal of Family Therapy, v. 24, p. 153-173, 1996.

KATZ, S. Disciplining Old Age. The Formation of Gerontological Knowledge, Cambridge: Cambridge University Press, 1996.

KATZ, S. "Busy Bodies: Activity, Aging, and the Management of Everyday Life" Journal of Aging Studies, v. 14, p. 135-152, 2000. 
KEMP, J.; KEMP, E. Older Couples, New Romances, Finding and Keeping Love in Later Life. Toronto: Celestial Arts, 2002.

KLEIN, A. Imágenes del adolescente desde el psicoanálisis y el imaginario social. Condiciones de surgimiento de la adolescencia desde la modernidad y el disciplinamiento adolescentizante desde la pos-modernidad. Uruguay: Psicolibros, 2002.

KLEIN, A. Escritos psicoanalíticos sobre Psicoterapia, Adolescencia y Grupo. Uruguay: Psicolibro-Waslala, 2003.

KLEIN, A. Adolescentes sin adolescencia: reflexiones en torno a la construcción de subjetividad adolescente bajo el contexto neoliberal. Uruguay: Psicolibro- Universitario, 2006.

KLEIN, A. "Neoliberalismo-Neoevangelismo-Cambios socio-demográficos. Posibles marcos epistemológicos frente a algunos desafíos actuales en el campo de las ciencias sociales (los paradigmas ambiguos)". Acciones e Investigación en Ciencias Sociales, v. 27, p. 69-109, 2010a.

KLEIN, A. "Nuevas formas de relacionamiento abuelos-nietos adolescentes desde los cambios demográficos-sociales actuales”. Psicología Revista, São Paulo, v. 18, n. 1, p. 1-25, 2010 b.

KLEIN, A. "Nuevas formas de Familias, Paternidades y Relaciones Familiares como Modelo de Intersecciones Intergeneracionales”. Ageing Horizons, Oxford, v. 20, p. 23-35, 2010c.

KLEIN, A. Subjetividad, Familias y Lazo social. Procesos psicosociales emergentes. Buenos Aires: Ediciones Manantial, 2013.

LEE, R.; MASON, A. "Fertility, Human Capital, y Economic Growth over the Demographic Transition”. European Journal Population, v. 26, n. 2, p. 159-182, 2010.

LEESON, G.; HARPER, S. "Attitudes to Ageing and Later Life". The Global Ageing Survey (Research report 106). Oxford: The Oxford Institute of Ageing, 2006.

LEESON, G.; HARPER, S. "Attitudes to Ageing and Later Life". The Global Ageing Survey (Research report 107). Oxford: The Oxford Institute of Ageing, 2007.

LEESON, G.; HARPER, S. “Ageing and Later Life. The Americas”. Global Ageing Survey. Research report 207. Oxford: The Oxford Institute of Ageing, 2007a.

LEESON, G.; HARPER, S. “Ageing and Later Life. Hong Kong and Asia”. Global Ageing Survey. Research report 307. Oxford: The Oxford Institute of Ageing, $2007 \mathrm{~b}$.

LEESON, G. “Demography, Politics and Policy in Europe”. In LUDLOW, P. (Ed.). Setting EU Priorities 2009. Ponte de Lima: The European Strategy Forum, 2009, p. 102-124.

LEESON, G. "The demographics of population ageing in Latin America, the Caribbean and the Iberian Peninsula, 1950-2050". In MONTES DE OCA, V. (Coord.). La agenda del Envejecimiento y las Políticas Públicas Hoy. Mexico: Instituto de Investigaciones Sociales, Unam, 2013, p. 53-74. 
LEESON, G.; HARPER, S. "Some Descriptive Findings from the Global Ageing Survey" (Research report, 108). Oxford: The Oxford Institute of Ageing, 2008.

LÓPEZ LA VERA, B. La transición entre ocupar el tiempo libre y empoderar, perspectivas de la educación universitaria dirigida al adulto mayor. Ageing Horizons, v. 9, p. 82-99, 2010.

LÓPEZ LA VERA, B. "Empoderamiento y adultos mayores. Impacto de la participación de un grupo de adultos mayores en un programa educativo". In MONTES DE OCA, V. (Coord.). La agenda del Envejecimiento y las Políticas Públicas Hoy. México: Instituto de Investigaciones Sociales, Unam, 2013, p. 207-248.

MANCINAS ESPINOZA, S.; GARAY VILLEGAS, S. Familia, envejecimiento y políticas sociales. En MONTES de OCA, V. (Coord.). La agenda del Envejecimiento y las Políticas Públicas Hoy. Mexico: Instituto de Investigaciones Sociales, p. 395-424, 2013.

MEJÍA, S. Resistencia y acción colectiva de las mujeres nahuas de Cuetzalan: ¿Construcción de un feminismo indígena?. Tesis de Doctorado, Posgrado en Desarrollo Rural, Universidad Autónoma Metropolitana, México, 2010.

MENDES DE LEON, C. et al. "Social Networks y Disability Transitions across Eight Intervals of Yearly Data in the New Haven epese". Journal of Gerontology, Behavior Psychology y Social Sciences, v. 54, n. 3, p. 162-172, 1999.

MEYROWITZ, J. No Sense of Place: The Impact of Electronic Media on Social Behaviour. New York: Oxford University Press, 1984.

MONTES DE OCA, V. "Envejecimiento y protección familiar en México, límites y potencialidades del apoyo al interior del hogar". In ARIZA, M.; OLIVEIRA, O. (Coords.), Imágenes de la Familia en el Cambio de Siglo. México: Instituto de Investigaciones Sociales UNAM, p. 510-563, 2004.

MONTES DE OCA, V. "Families y intergenerational solidarity in Mexico, challenges y opportunities. - Seminar on "Family support networks y population ageing-2009", 2009. Recuperado de http,//www.unfpa.org/webdav/site/global/shared/documents/publications/2010/ family support networks2009.pdf.

MORAGAS, R. Gerontología social, envejecimiento y calidad de vida. Barcelona: Herder, 1991.

MUCHINIK, E. Hacia una nueva imagen de la vejez. Buenos Aires: Belgrano, 1984.

NEUGARTEN, B. Personality in Middle and Late Life. New York: Atherton Press, 1964.

NEUGARTEN, B. Los significados de la edad. Barcelona: Herder, 1999.

NINA-ESTRELLA, R. (2004). “Sabor a mí... Pareja y vejez”. In SÁNCHEZ, C. (Ed.). Familia y persona de edad mayor. San Juan: Proyecto Atlantea, p. 117-130.

NOLLER, P.; FITZPATRICK, M. A. Communication in Family Relationships. NJ: Prentice Hall, 1993. 
PARKER, R. "How Partners in Long-Term Relationships View Marriage”. Family Matters, v. 55 , p. $74-88,2000$.

PICK, S. et al. "Escala para medir agencia personal y empoderamiento (Esage)". Interamerican Journal of Psychology, v. 41, p. 295-304, 2007.

ROSOW, I. Social Integration of the Aged. New York: Free Press, 1963.

ROWE, J.; KAHN, R. “Successful Ageing”. The Gerontologist, v. 37, n. 4, p. 433-440, 1997.

ROWE, J.; KAHN, R. Successful Aging. New York: Pantheon., 1998.

SÁNCHEZ, A. "Dispositivos de empoderamiento para el desarrollo psicosocial". Revista Universitas Psychologica, Bogotá, v. 1, n. 2, p. 39-48, 2002.

SORIA, C. "Empoderamiento, un medio, no un fin". In Empoderamiento, ¿tomar las riendas? Quito: Plataforma Latinoamericana de Gestión de Conocimientos, 2006, p. 45-51.

UCHINO, B. et al. "The Relationship between Social Support y Physiological Processes, A Review with Emphasis on Underlying Mechanisms y Implications for Health". Psychological Bulletin, v. 119, n. 3, p. 488-453, 1996.

UNITED NATIONS. "World Population Prospects. The 2010 Revision”. New York: United Nations, 2010.

VILLAR, F. (2013). "Desafíos de la investigación interdisciplinaria en gerontología". In MONTES DE OCA, V. (Coord.). La agenda del Envejecimiento y las Políticas Públicas Hoy. Mexico: Instituto de Investigaciones Sociales, Unam, 2013, p. 189-206.

VILLAGÓMEZ ORNELAS, P. EI envejecimiento demográfico en México: niveles, tendencias y reflexiones en torno a la población de adultos mayores. México: Instituto de Geriatría, 2009.

VIVEROS MADARIAGA, A. Envejecimiento y vejez en América Latina y el Caribe: políticas públicas y las acciones de la sociedad. Santiago de Chile: Celade, 2001.

Submissão em: 04/09/2017

Aceite em: 25/11/2017

Alejandro Klein es profesor investigador de la Universidad de Guanajuato. Division De Ciencias Sociales y Humanidades, Campus Leon, Universidad De Guanajuato. México. Dirección para correspondência: División de Ciencias Sociales y Humanidades. Universidad de Guanajuato - Campus León. Blvd. Puente Milenio No. 1001 Fracción del Predio San Carlos. C.P. 37670. 
León, Guanajuato. México.

E-mail: mailto:alejandroklein@hotmail.com

Erika Carcaño es profesora investigadora de la Universidad De Guanajuato. Division De Ciencias Sociales y Humanidades, Campus Leon, Universidad De Guanajuato. México. E-mail: mailto:erikacarcano@,gmail.com 